BMJ Open

Diabetes

Research

\& Care

\title{
Using a community-based participatory research approach to meaningfully engage those with lived experience of diabetes and homelessness
}

\author{
David J T Campbell (1) , ${ }^{1,2,3}$ Rachel B Campbell, ${ }^{1}$ Anna DiGiandomenico, ${ }^{4}$ \\ Matthew Larsen, ${ }^{1,4}$ Marleane A Davidson, ${ }^{4}$ Kerry McBrien, ${ }^{2,5}$ Gillian L Booth, ${ }^{6,7}$ \\ Stephen W Hwang ${ }^{6,7}$
}

\begin{abstract}
To cite: Campbell DJT, Campbell RB,

DiGiandomenico A, et al. Using a community-based participatory research approach to meaningfully engage those with lived experience of diabetes and homelessness. BMJ Open Diab Res Care 2021;9:e002154. doi:10.1136/ bmjdrc-2021-002154
\end{abstract}

- Supplemental material is published online only. To view, please visit the journal online (http://dx.doi.org/10.1136/ bmjdrc-2021-002154).

Received 20 January 2021 Accepted 26 June 2021
Check for updates

\section{(C) Author(s) (or their} employer(s)) 2021. Re-use permitted under CC BY-NC. No commercial re-use. See rights and permissions. Published by BMJ.

For numbered affiliations see end of article.

Correspondence to Dr David J T Campbell; dcampbel@ucalgary.ca

\section{ABSTRACT}

Introduction Participatory research is a study method that engages patients in research programs, ideally from study design through to dissemination. It is not commonly used in diabetes health services research. Our objectives were to describe the process and challenges of conducting a participatory research project and to highlight the experiences of both patient co-researchers and academic researchers.

Research design and methods We recruited people with lived experience of homelessness (PWLEH) and diabetes in Toronto, Canada to become patient co-researchers. They were asked to commit to attending biweekly meetings. We undertook two major research projects: concept mapping to choose a research focus; and photovoice to explore accessing healthy food while homeless. We used a convergent mixed-methods design to evaluate their experience.

Results A diverse group of eight PWLEH had an average attendance of $82 \%$ over 21 meetings-despite this success, we encountered a number of challenges of conducting this research: funding, ethics approval and recruitment were particularly difficult. Group members reported that participation improved their ability to self-advocate in their diabetes care and provided them with tangible skills and social benefits. Group members stated that they valued being involved in all aspects of the research, in particular knowledge translation activities, including advocating for nutritious food at shelters; presenting to stakeholders; and meeting with policymakers.

Conclusions The use of participatory research methods enables academic researchers to support community members in pursuing research that is pertinent to them and which has a positive impact. In our study, coresearchers contributed in meaningful ways and also valued the experience.

\section{INTRODUCTION}

The importance of engaging patients in all aspects of developing healthcare policies has been widely acknowledged. ${ }^{1}$ The definition of patient-oriented research, or patient engagement research, is broad and includes research

\section{Significance of this study}

What is already known about this subject?

- Patient-oriented research is important to public health research as it helps with the development of relevant interventions and knowledge translation.

- Participatory research is a form of research that maximally involves patients in all phases of the research. This methodology is not commonly used in research on diabetes and diabetes-related interventions.

\section{What are the new findings?}

- Patient engagement is important for studies involving socially disadvantaged populations with diabetes.

- Community members involved in research not only contribute substantially to research projects but also find the experience to be enriching and valuable.

How might these results change the focus of research or clinical practice?

- Those who conduct research with and develop programs to provide diabetes care, especially to socially disadvantaged populations, should involve community members through all phases of the process to ensure the intervention is maximally useful for patients.

that involves patients in a variety of capacities. $^{23}$ Arnstein originally described citizen participation as a spectrum on a 'ladder of participation', ranging from simply collecting data from informants or subjects to processes where citizens are fully engaged at all stages. ${ }^{4}$ Typically, participatory research studies are those towards the top of this ladder-those which give patients or citizens increased levels of power in the process, including: Partnership, Delegated Power, and Citizen Control. ${ }^{4}$

One particular form of patient engagement research is Community-Based Participatory Research (CBPR); where patients 
or community members are viewed as co-researchers, rather than as study subjects or participants. ${ }^{5}$ CBPR has been used extensively in social work research, ${ }^{6}$ in international settings, ${ }^{7}$ and more recently in health services research. ${ }^{8}$ Participatory research approaches have been used robustly in the field of diabetes prevention/health promotion. ${ }^{9-12}$ They have also been used occasionally in research on diabetes management, ${ }^{13-15}$ however a recent realist review found a total of only 29 diabetes-related studies in which patients or community members actively contributed to research projects in more involved ways than being traditional informants. ${ }^{16}$

CBPR and patient-engagement research may have a particularly important role in areas of health research focused on equity and the social determinants of health. ${ }^{17}$ We were interested in inequities in diabetes management and outcomes with respect to people with lived experience of homelessness (PWLEH). PWLEH are known to have more difficulties managing their diabetes ${ }^{18}$ and are more likely to accrue diabetes-related complications. ${ }^{19}$ There are many potential explanations for these disparities in diabetes outcomes, as PWLEH face a number of barriers including: mistrust of the healthcare system, ${ }^{20}$ lack of health insurance coverage,$^{21}$ and difficulty accessing healthy foods. ${ }^{22}$ Furthermore, typical diabetes care models may not service this population optimally. ${ }^{23}$ While the above-cited studies have highlighted the difficulty of managing diabetes while experiencing homelessness, and others have used participatory approaches to understand general health needs in this population, ${ }^{24} 25$ we are unaware of any previous study that used participatory methods to give voice to this particular population with regard to diabetes-specific challenges.

We used participatory methods (at the Partnership level of the participation ladder) to engage PWLEH and diabetes with the goal of empowering them to lead and undertake meaningful research initiatives. The objective of this paper is to describe the process of conducting this participatory project and to report the experiences of co-researchers with lived experience of homelessness and diabetes, giving voice to patients. Our specific aims were to:

1. Document our ability to engage this population in group research activities, and the challenges inherent in conducting patient engagement research with this population.

2. Explore the experiences of co-researchers who participated in the process.

3. Collate reflections of community co-researchers and academic researchers on aspects of the work that were most meaningful to them.

\section{METHODS}

Study design

From the outset, we envisioned an open-ended participatory patient-engagement project. The research approach taken in this work is grounded in the theoretical idea of 'giving voice' through social representation theory, ${ }^{26}$ which theorizes that 'knowledge is the outcome of social interaction'. ${ }^{27}$ The objective of giving voice has been described as 'empowering people to be heard who might otherwise remain silent'. ${ }^{28}$

In order to reach our objective, we recruited a group of PWLEH and diabetes to form the Clients with Diabetes Action Committee (CDAC) and used participatory research principles to guide them in developing research priorities and pursuing meaningful research activities. We were careful to keep the research topic and question as open-ended as possible to allow research priorities and questions to emerge from within the group rather than being imposed on group members by academic researchers and/or funding bodies.

\section{Setting and group composition}

We conducted this program of research in Toronto, Ontario-Canada's largest city (2017 population: 2930 000). Toronto is a city with high levels of ethnic and socioeconomic diversity. ${ }^{29}$ It is known for having very high housing costs, ${ }^{30}$ which contributes to it also having the greatest absolute number of people experiencing homelessness in Canada. ${ }^{31}$ Based on 2018 data, 8715 unique individuals experience homelessness on any given night in Toronto. ${ }^{32}$

We sought to include individuals who had recent experience managing diabetes in the context of homelessness. Therefore, eligibility criteria to join the CDAC included a self-reported history of living with diabetes (any type) while experiencing homelessness or housing instability at any point in the previous 2 years. We used the broad definition of homelessness endorsed by the Canadian Observatory on Homelessness: lacking 'stable, safe, permanent, appropriate housing, ${ }^{33}$ This includes individuals who are sleeping rough, emergency sheltered, provisionally accommodated, and precariously housed. We excluded anyone who had only diabetes risk factors, without a previous diagnosis of diabetes. Additional exclusion criteria included the inability to fluently converse in English and active severe mental illness that would preclude one's ability to participate in group research activities. Recruitment began in November 2018 and was complete by the end of January 2019. Participants had to commit to joining the group and attending approximately every other week from January to July 2019.

We recruited participants primarily through flyers that were posted in numerous downtown Toronto shelters, drop-ins, rooming houses, addiction recovery facilities, and community notice boards, as well as community health centers and programs, endocrinology clinics, and a community-based education and addiction recovery service. The flyers clearly outlined the eligibility criteria (diabetes and homelessness) and stated that participants would be compensated. Interested parties were encouraged to either contact the investigators by telephone or email, or to attend one of the group meetings, as dates 
and times for several meetings were included on the recruitment advertisements.

The group met regularly in a community space in Regent Park, a lower income area on the east side of downtown that was originally built as a public housing project in the 1940s. ${ }^{34}$ Participants were not necessarily residents of this area, but all were familiar with it, and most lived within walking distance. Initially, the group gathered for 2 hours every other week, and gradually moved to weekly meetings towards the end of the project. When individuals attended their first group meeting, they were introduced to the purpose and structure of the group and provided written informed consent to participate. They also signed a confidentiality agreement and a formal Terms of Reference (online supplemental appendix A). This document laid out the expectations for participation in the group, specifying who qualified for study honoraria and encouraging professionalism and mutual respect towards facilitators and peers. At the first group meeting, all participants were provided a $\$ 10$ gift card to a local coffee shop. To recognize the time and effort of regular group members, they were provided with two transit tokens and a \$C20 cash honorarium for each subsequent group meeting they attended. This amount was chosen as it approximated a working wage in Ontario. We spent roughly $40 \mathrm{~min}$ of each meeting sharing a meal and providing diabetes education, so we sought to compensate people for $80 \mathrm{~min}$ of research contribution. With a local minimum wage of $\$ \mathrm{C} 14 /$ hour, our $\$ 20$ stipend corresponds to a working rate. Co-researchers were also compensated at the same rate for work done outside group time.

\section{Group training}

Meetings were facilitated by two investigators (DJTC and $\mathrm{RBC}$ ), who were trained and experienced in qualitative methods and in working with PWLEH. Both had completed a training workshop on community-based participatory research and RBC had previously facilitated a community-based advocacy group. Neither had preexisting relationships with group members.

Initial group meetings began with a review of the Terms of Reference each member had signed. Group members and facilitators were encouraged to get to know one another using ice breakers and participating in social activities. During this part of the group meeting, coffee and a nutritious lunch was served to group members.

In order to empower co-researchers to become fully engaged in the research effort, we used several of our early group sessions to provide basic training in the purpose, fundamental principles, and methods used in academic health research. We employed and modified resources that others had used for participatory research in other unrelated contexts. ${ }^{35}$ During this process, group members received introductions to study methods used in participatory research, including designing surveys, conducting interviews, and using arts-based methods.
Many group members had not received basic diabetes education in the past, and/or lacked sufficient knowledge and understanding about diabetes management and complications to contextualize the personal challenges they and other members of their community were facing. Since this is a necessary step to enable the group to reach consensus on topics fit for research, we planned that diabetes education would be a recurring core element of group meetings. The remainder of group meeting time was devoted to pursuing the scholarly activities proposed by the group (as described in detail below) and making plans for future meetings.

\section{Research activities}

Having community members decide which research questions are most important to address is a fundamental component of participatory research. At the outset it was clear that group members each had priorities and interests that were primarily driven by their own experiences of managing diabetes while experiencing homelessness. In order to concisely synthesize the group's priorities, we used a participatory research methodology known as concept mapping, which has been used extensively to help identify priorities for particular groups. ${ }^{36}$ The details of the concept mapping process and results are published separately. ${ }^{37}$ Through an iterative process which included brainstorming, sorting, rating, and discussion, our group members identified that the collective preference for our group's research activity would be on how homelessness affects one's ability to access healthy foods which, in turn, impacts diabetes management and outcomes.

Once the results of the concept mapping exercise were analyzed, the group facilitators presented different research methodologies that could be used to explore this topic further, including quantitative methods (such as surveys) and qualitative methods (such as focus groups), as well as arts-based methods (such as photovoice and documentary film). The group collectively decided to pursue a project based on the classic photovoice methodology, as described by Wang and Burris. ${ }^{38}$ The photovoice project is also documented in a separate publication. ${ }^{39}$ Group members were tasked with taking photographs that illustrated each of the following specific research questions:

- What makes it challenging to eat well with diabetes while experiencing homelessness?

- What about homelessness has been a major help or barrier to diabetes self-management?

Group members then showed their photos to each other and to the facilitators. They chose which photo they wanted to use and developed a narrative to accompany the photo, aided by the facilitators using photo elicitation techniques. ${ }^{40}$

The photos and narratives resulting from the photovoice project were mounted and framed. They were displayed alongside the biographies of the photographers. The photo exhibit, and descriptions of this program of research were presented at local hospitals, research 
institutes, and public exhibition spaces in Calgary and Toronto, in addition to national conferences including: Diabetes Canada (Winnipeg, Manitoba, October 2019), Canadian Alliance to End Homelessness (Edmonton, Alberta, November 2019), North American Primary Care Research Group (Toronto, Ontario, November 2019).

\section{Evaluation methods}

We undertook a convergent mixed-methods evaluation of our participatory research activities after completion of the study. First, we gathered information on attendance of group members at meetings. We also sought to allow them to provide feedback on the experience and to understand the challenges inherent in conducting this type of research with this population. To do so, we conducted anonymized surveys (online supplemental appendix B) and an open-ended focus group at the conclusion of the group meetings in July 2019, with the latter facilitated by colleagues not previously engaged with the group. After a 4-month hiatus, we recalled group members and conducted a final semistructured interview to ask them about how their participation impacted their lives, and what might have changed for them due to their participation.

Interview responses and focus group transcripts were analyzed using directed qualitative content analysis, ${ }^{41}$ following a predominantly deductive approach with the preliminary coding template being based largely on the questions asked in the quantitative survey: (1) diabetes knowledge, (2) tangible skills, (3) challenges and suggestions for improvement. Within each of these broad categories, responses were coded according to similarity. Interview transcripts were analyzed independently by two reviewers with experience in qualitative data analysis (DJTC and RBC). Multiple reviewers were used to provide a diversity of perspectives on the data rather than seeking convergence. Results from the various methods were triangulated to provide qualitative support for the patterns reported in the quantitative survey.

Finally, we asked some group members and the academic investigators who were closely involved with data collection to provide a statement reflecting on their experience and the impact of their participation in this research.

\section{RESULTS}

\section{Group composition, engagement and challenges}

We were contacted by 28 individuals who initially expressed interest in being part of the group. Sixteen (16) of those individuals came to at least one group meeting. Of those who attended one meeting, five were ineligible to participate as they did not have diabetes, based on self-report. The remaining 11 individuals agreed to become part of the recurring group. Three participants did not return after the initial group meeting, and eight continued to participate throughout the entire duration of the study. Our eight group members included five women and three men, with ages ranging from 36 to 73 years. Four reported having diabetes complications while four stated that they had no complications. The majority of group members were white $(n=5)$, two were black and one was Indigenous (table 1).

The attendance rate for the eight regular group members was $82 \%$. Individual attendance ranged from $48 \%$ (10 of 21 meetings) to $100 \%$ (21 of 21 meetings), with an individual mean of $80 \%$. Two academic investigators (DJTC and RBC) attended all group meetings, teaching the diabetes education portion of meetings, and facilitating group discussions and activities during the remainder of the group time. While the attendance rate provides one measure of the success of the group in engaging members of the community as co-researchers, so too do the achievements of the group. The CDAC was able to complete the concept mapping ${ }^{37}$ and photovoice project, ${ }^{39}$ with results being presented to relevant stakeholders across the country. Our participants described that we were successful in our objective of providing them with a voice, one group member stated: "it was overwhelming, but in the same breath empowering. Like it was so empowering that, you know, we were able to tell our story and people listened" (P5). One individual described how participation in the group helped them feel like they were contributing meaningfully: "it shows that I can do something like to help the homelessness and the diabetics. Like I can be of some help to society, generally some help instead of just sleeping all day in the shelters" (P7). Another stated: "I learned that for me it's about giving, sharing... giving my story out there, right?... being there to help others, you know" (P4).

We noted a number of challenges that occurred during the conduct of this research. When some regularly attending group members missed meetings, we later discovered they had been in hospital. Half of our group members had health issues that caused them to visit emergency departments or acute care hospitals during the 6 months of the group meetings, with three of them having three or more acute care visits in that time. Another challenge in working with this population was difficulty maintaining contact with group members. Four out of the eight group members lost or had their cellphones disconnected during the study period. Similarly, five of eight group members moved residences during the 6-month period, some multiple times. Future studies could consider providing participants prepaid cell phones or minutes to facilitate ongoing contact.

\section{Participant experience}

The surveys administered and content analysis of the interviews revealed three areas of interest to help understand participants' experiences of the program. These included: (1) improvements in diabetes knowledge and self-efficacy; (2) acquisition of tangible skills and social benefits from participation; and (3) suggestions for improving the group research experience. The 


\begin{tabular}{|c|c|c|}
\hline \multirow[t]{3}{*}{ Age } & $<45$ years & 2 \\
\hline & 45-64 years & 4 \\
\hline & $65+$ years & 2 \\
\hline \multirow[t]{2}{*}{ Gender } & Woman & 5 \\
\hline & Man & 3 \\
\hline \multirow[t]{2}{*}{ Ethnicity } & White/Caucasian & 5 \\
\hline & Other & 3 \\
\hline \multirow{4}{*}{$\begin{array}{l}\text { Housing status at } \\
\text { beginning of study }\end{array}$} & Rough sleeping & 1 \\
\hline & Stable resident of shelter & 2 \\
\hline & $\begin{array}{l}\text { Transitional or temporary } \\
\text { housing }\end{array}$ & 2 \\
\hline & Tenuously/unstably housed & 3 \\
\hline \multirow{2}{*}{$\begin{array}{l}\text { Duration of } \\
\text { homelessness/ } \\
\text { unstable housing }\end{array}$} & Range & $\begin{array}{l}8 \text { months }-12 \\
\text { years }\end{array}$ \\
\hline & Mean & 2.81 years \\
\hline \multirow[t]{2}{*}{ Diabetes type } & Type 1 & 0 \\
\hline & Type 2 & 8 \\
\hline \multirow[t]{2}{*}{ Duration of diabetes } & Range & $\begin{array}{l}18 \\
\text { months-23 } \\
\text { years }\end{array}$ \\
\hline & Mean & 7.21 years \\
\hline \multirow[t]{3}{*}{ Diabetes treatment } & $\begin{array}{l}\text { Lifestyle only (no medical } \\
\text { therapy) }\end{array}$ & 2 \\
\hline & $\begin{array}{l}\text { Non-insulin medications } \\
\text { only }\end{array}$ & 3 \\
\hline & $\begin{array}{l}\text { Insulin injections } \pm \text { other } \\
\text { medications }\end{array}$ & 3 \\
\hline
\end{tabular}

Diabetes care

providers

\begin{tabular}{lll} 
Medical doctor & Primary care only & 5 \\
Allied health & Specialist involvement & 3 \\
providers & Nurse/diabetes educator & 1 \\
& Dietitian/diabetes educator & 2 \\
Diabetes & Pharmacist & 1 \\
complications (self- & Coronary disease/ & 2 \\
reported) & myocardial infarction & \\
& Stroke/cerebrovascular & 2 \\
& accident & \\
& Foot ulcers (wounds), & 1 \\
& gangrene, amputations & \\
& Diabetic nephropathy & 1 \\
& Diabetic retinopathy & 1 \\
& Neuropathy symptoms & 5 \\
Comorbidities (self- & Hypertension & 7 \\
reported) & Hypercholesterolemia & 5 \\
& Obesity & 6 \\
& Sleep apnea & 4 \\
& Depression & 6 \\
& Anxiety problems & 4 \\
& Psychosis & 2 \\
& Alcohol addiction & 4 \\
& Drug addiction & 5 \\
\hline & & \\
\hline
\end{tabular}

convergent results from both quantitative and qualitative data are presented together below.

\section{Diabetes knowledge and self-efficacy}

Seven out of eight group members rated their knowledge of diabetes as poor ( 4 of 8 ) or fair ( 3 of 8 ) prior to participating in the group. One group member stated about his prior diabetes knowledge: "it was very poor, I didn't know much. Just that basically high blood sugar and low blood sugar, all of them are bad" (P1). Another stated: "I didn't know anything at all about diabetes - nor was I interested in learning anything about it" $(\mathrm{P} 7)$.

After the group, all of these individuals rated their knowledge as good $(n=1)$, very good $(n=5)$ or excellent $(n=1)$. Participants described having acquired knowledge about diabetes complications: "it's not just the sugar, but it's also foot care and your eyes, and overall nerve damage... before I wasn't aware of all that stuff" (P5); and the pathophysiology of how these problems arise: "damage to the blood vessels like the scarring, can lead to a build up of plaque and all kinds of problems" (P1). Several participants remarked that they gained an appreciation of the importance of diabetes self-management: "the more you do to address the complications that diabetes can cause, I think the more healthier it will make you" (P2).

Furthermore, group members expressed a variety of changes that happened with their diabetes care and selfmanagement as a result of things they learned during the group's diabetes education sessions. One said that they were now "connecting with specialists and doing the maintenance" (P4), while another said that they had "added [new medication], joined a weight loss clinic, and taking fasting blood sugar measurements more often" (P1). Another group member stated: "I think I will be looking into joining diabetes education centres" (P2), as a result of their participation in the group sessions.

Finally, a number of group members felt that their participation in group activities increased their ability to self-advocate for their healthcare needs. One stated: "I would say it gave all of the different pieces of information. It helped me establish my priorities for me to pursue with my doctor" (P2). Another said:

[the group] taught me how to ask what I want. I realized

I'm in control of my own healthcare and I have to ask specific questions, right? I have to be the one that has to be up there jumping up and down and asking for what I want or what I need... to actually have a doctor here that we can pick their brain you know, it was actually beneficial. (P4)

\section{Tangible skills and social benefits to participants}

All group members identified that they gained tangible skills, which included: working together with a group, learning photography skills, and contributing to academic research projects. However, the most valued aspects of participation were the social opportunities afforded by the group. A group member stated: 
"Camaraderie among group members was great" (P1). Others formed social connections that persisted outside of the group: "any time I think that I might be eating something that I shouldn't be eating, I call one of the group members and be like - yo can I eat this?" (P4). Finally, one said: "I was in crisis, you know, and was not getting the help that I needed from the agencies, but I think coming to this group kept me going, you know, because I was doing something and I was learning" (P6). Finally, one summed up the social impact of the group by stating: "we are not alone and we supported each other and we laughed, we giggled, we cried... we became friends" (P5).

\section{Challenges and suggestions for improvements}

As mentioned above, a number of group members identified that camaraderie was a strength of the group, however, the confluence of personalities also posed a challenge at times. One participant stated: "I hated sometimes being stuck in a room for two hours with people I didn't get along with" (P4). To deal with these challenges, some group members suggested having more clear expectations: "so the boundaries are pretty clear like what we are talking about, just so people don't get super upset or like everybody feels like they have a voice" (P4), or reiterating these expectations more clearly at the outset of each group meeting. Another group member suggested that group interactions may have been aided if facilitators had formal training in trauma-informed care or social work practice.

One participant stated that participating in the group was somewhat triggering and would have been strengthened by having more resources on hand: "when I was doing the photo it dragged up a lot stuff that I was remembering being homeless and going through stuff and I don't have quite the support that I should have" (P6).

Similarly, another participant mentioned that participating in the photovoice exhibit was difficult: "I was overwhelmed, excited, just overwhelmed. It was very nervous for me, but turned out good in the end" (P3).

Co-researchers commented that while they appreciated the food provided during meetings they would have valued more diversity and that it was a missed opportunity for dietary education: "when it comes to the basic foods that we actually ate we never actually looked at the array of foods that diabetics can eat and how that can be, how you can actually use those kinds of foods" (P2). Other related feedback was that cognitive-behavioural therapy approaches could have been implemented to help participants with their diabetes self-management.

In addition to the participant experience data presented above, both academic and community-based researchers were asked to reflect on the experience and the value of their participation. Their detailed openended reflections are presented in table 2.

\section{DISCUSSION}

Our participatory research project involved members of the community who had lived experience of homelessness and diabetes in a participatory fashion, empowering them to work alongside the academic investigators as co-researchers. We were able to elicit their shared priorities and subsequently explore these using photovoice. Because they were involved from the outset, group members helped translate the study findings to community decision-makers. The experience was largely positive for our group members, as they described a number of benefits they received through their participation in the group, including both benefits to their health and diabetes management, as well as other tangible and social benefits. Interestingly, the benefits that were described by participants reached far beyond what was initially envisioned by study investigators at the outset of the project (ie, enhanced diabetes knowledge, photography skills). Participants felt that some of the most important benefits they received from the study were intangible: feeling respected, valued, and heard; having a sense of accomplishment and purpose, which led to increased self-efficacy in other domains; and developing a community of people with whom they shared many life experiences. This finding is similar to what has been seen in other studies using participatory research. ${ }^{42}$ Context, group dynamics, community centeredness, and research design have been elicited as key elements of participatory research. ${ }^{43}$ As shown in our data, each of these played a key role in the success of our project.

Patient-oriented research, or patient engagement, is becoming increasingly important in health services research, as the academic community comes to realize that input from target groups is crucial to the success of health interventions. ${ }^{44}$ However, a great deal of the 'patient-oriented research' in this area is still done with relatively little engagement, or a low level of participation of patients-who often have a minor advisory or consultation role, and who may be used in a tokenistic fashion. ${ }^{45}$ That said, there are many examples of high-quality CBPR studies in diabetes prevention and health promotion. ${ }^{9-12}$ However, when it comes to studies on diabetes treatment or management, these approaches are used, ${ }^{13-15}$ but are much less common. ${ }^{16}$

Our reflections on the process of conducting a participatory research project document the impact of the participatory process on the researchers and the research. Impact in participatory research has been defined as 'the many forms of change that occur with, within and for those who are engaging in the research as well as those changes that occur across the wider complex socio-ecological system or set of systems' ${ }^{46}$ These reflections and the data presented in this manuscript highlight impact in a number of forms: alterations to the planned research; evidence of surprise to 'experts'; exploring unexpected phenomena/problems; and the stories of changes people have made through their involvement (both academics and community researchers). ${ }^{46}$ 


\section{Academic researchers}

DJTC: Being a diabetologist with a clinical practice focused on caring for those who face social vulnerabilities (many of whom have been homeless), I thought that I had a good sense of the types of barriers my patients face and what their priorities would be. However, doing this patient-led project taught me how absolutely critical it is to meaningfully engage those with lived experience, as their priorities are likely to be different than what a provider might anticipate them to be. The findings from this study continue to inform my ongoing research and advocacy efforts. Given the centrality of access to healthy foods raised by this research, I am creating new programs and initiatives with the aim of addressing food insecurity in patients with diabetes. ${ }^{54}$ Also, as the coordination of healthcare visits was raised by the group, I am now pursuing a new line of research to pilot test a comprehensive diabetes care model in those experiencing homelessness to reduce this burden for patients similar to those in our group.

RBC: I have been working in homelessness policy and research for 15 years. Though I have never been a front-line service provider, I have worked with clients in focus groups, advocacy groups, and during research events. My participation in this community-based research project taught me that researchers and policy makers need to work with individuals with lived experience of homelessness on an individual, face-to-face level, regardless of their role or position. The lessons I learned from CDAC members through sharing the nuances of their lived experience are indispensable. Despite reading academic literature and having a pulse on the world of homelessness, I found the work that the group did to be deeply moving- and still do every time I revisit it. The development of the group's research priorities and questions serves as a constant reminder that academics are not necessarily on the same page as the those with lived experience in this regard. Academics will never know what clients/patients prioritize unless they engage with the community and enable individuals to partner meaningfully in research endeavors.

SWH: I have worked in homelessness-related health research for over 20 years and have led a number of projects related to diabetes. Being involved with this project, however, was a unique experience. Having individuals who have lived with homelessness and diabetes to lead the direction of the research provided new insights from a firsthand perspective and yielded meaningful results. On the heels of this patient-led program of research, my team has launched a communitybased group to continue bringing the voices of people with lived experience of homelessness to research priorities at our centre. We will also use the insights from this study to help guide our homelessfocused primary care teams as they work with patients with diabetes. In this way, the efforts of the Clients with Diabetes Action Committee live on.

\section{Community group members}

\section{ML: Information about diabetes from the CDAC group facilitators} deepened my understanding of how my diet and level of activity have a direct impact on my health outcomes. In talking with other group members I learned of helpful services that I could utilize, such as food banks with access to fresh produce and drop-ins serving nutritious food. More so, listening to group members share about their personal journeys with diabetes and homelessness, I began to understand how one can exacerbate the other.

In learning about different research methods and contributing photos and writing about my experiences, I came to understand that my contribution to the study was legitimate. Brainstorming as a group with my peers on a research question demonstrated to me that the facilitators were interested in addressing issues that mattered to myself and others who have had a similar journey. In November 2019 I was able to attend and present at the Canadian Alliance to End Homelessness conference. I also had the opportunity to share my experience with the CDAC in an interview with a reporter. ${ }^{55}$ Talking to professionals allowed me to bring attention to issues that are important to me and demonstrated that my lived experience is valuable to people who were in a position to help others like myself.

AD: At 56 I found myself homeless and fighting diabetes. That's when I joined an amazing group of people, the Clients with Diabetes Action Committee. I was given a voice from them. The group was made up of all walks of life but we shared one common ground, we all wanted to be involved in a cause that touched our lives, it made me feel that my story was important. We were involved in choosing the topics that were important to us and being able to share our stories with the other members of the committee. It was an empowering experience knowing that I was not alone.

Since getting involved with the CDAC, I have been able to share my experience on two podcasts ${ }^{56} 57$ and in November 2019 I was given the opportunity to present our research at two national conferences, one on diabetes and one on homelessness. Being able to share my experience with other researchers and doctors, ignited a fire within me. There I also had the pleasure of meeting the federal politician from my local constituency and was able to share my experience with him. $\mathrm{He}$ was interested in listening to my story. When I returned to Toronto he followed up with me. He directed me to other politicians and before COVID he was helping me to bring our Photo Exhibit to City Hall to tell our story. This experience have me a voice that has kept me focused on fighting for my rights. I will never let the light go out.

MAD: My experience with the CDAC group was challenging and educational. Within the classroom sharing our experiences as individuals without appropriate housing and chronic health history was quite triggering. We all had very challenging disclosures and at times there were behaviours. I really enjoyed attending the various venues outside of the classroom. When we did our photo exhibits, this was a great opportunity to have my voice heard. I met many people that were unaware of what individuals without appropriate housing are faced with or the many different reasons we all had for being on the streets as an adult or youth. The people I spoke with were unaware that youths deal with violence and abusive situations and some adults are graduates and are employed. This was my comfort level, speaking with total strangers that I would never see again, this was a lot better than engaging with my classmates that I saw weekly.

I also enjoyed when we had guest speakers; a representative from Diabetes Canada spoke to our group and was open to a Q\&A after. I spoke about my own experiences coping with type 2 diabetes and I got a chance to be featured in a national magazine ${ }^{58}$ and a national newspaper. ${ }^{59}$ I really wished that I had more opportunities to connect with policy makers. I believe that policy makers have no idea the barriers they create when they implement guidelines and rules. I am sure they have the statistics but it seems that they really don't care. 
Participatory research with community members who face significant social disadvantages can be challenging, as we demonstrated, with half of our participants facing acute health challenges that precluded their participation for a time. The social instability faced by this population can also hinder engagement in research, as was demonstrated by frequent changes in residence and telephone numbers during the study period-this, too, had previously been described in the literature. ${ }^{47}$ As indicated in reflections from several of our group members, additional support resources and specific training in trauma-based care would have been helpful. Many group members had previous experience participating in community-based group programming and seemed to bring expectations from those experiences to the CDAC. Given the centrality of this feedback, future CBPR studies led by the authors will have more explicit plans for assisting group members with these potential emotional and stress-related challenges.

There is a multiplicity of other challenges with this kind of work as has been described previously, ${ }^{48}$ including securing funding and getting approval from research ethics boards at the outset, when a discrete research question or methodology has not yet been identified. In our case, this required a flexible funder, and a very basic initial ethics application with numerous subsequent modifications as the study evolved. With respect to compensation, best practice in patient-oriented research states that participants should be compensated as they are providing time, knowledge and expertise, ${ }^{49}$ yet this needs to be balanced with the possibility that compensation may be coercive to a socially disadvantaged population, as it may provide an incentive for them to participate when in fact they do not wish to do so. ${ }^{50}$ Finally, this type of work is exceptionally time consuming for the investigators/group facilitators and requires the ability to manage group dynamics and individual personalities in a way that maintains the productivity of group meetings.

Despite these challenges, there are a number of important benefits to using participatory approaches that researchers should consider. First, because the community was involved with the planning and conducting of the research, we feel confident that through our participatory priority setting exercise (concept mapping), we were able to identify a topic that was of interest to the community. Other participatory studies have similarly used priority setting techniques to identify relevant topics for future study. ${ }^{51} 52$ Furthermore, in our participatory project, we were able to maintain group member engagement and participation through the entire process, including dissemination of the findings to relevant stakeholders. This degree of sustained engagement is not always achieved through all phases of the research. ${ }^{53}$ We were likely successful in this regard due to the frequent contact and effective delegation of tasks to group members, in addition to the compressed time frame of this research, meaning there was no lull in their participation.
Despite the many intrinsic strengths of this methodology, there are certainly limitations that warrant consideration. While we engaged a diverse group, which included both men and women of multiple ethnic backgrounds, and a variety of diabetes-related presentations (ie, complications, treatments, and diabetes duration), we certainly did not have representation from all groups. In particular, we did not capture the perspectives of those living with type 1 diabetes. Therefore, many potential concerns around insulin titration and hypoglycemia were not strongly represented in the knowledge that was co-created. Finally, because of the context-specific nature of this type of research, the generalizability of these findings to other settings is unclear.

This study offers valuable experience regarding the use of participatory patient-engagement research in studying diabetes experiences in a traditionally underserved population. Participatory research studies that engage similar populations should use methods that maximally involve patients as co-researchers. This type of work is not without challenges, but has a number of advantages over traditional research approaches. We feel that this methodology can provide an important starting point for defining and understanding the priorities of communities with whom researchers can partner to improve healthcare service delivery. Researchers might consider starting research programs with community engaged work of this nature-but conscious effort is required to maintain participant engagement through to the dissemination phase of the research. Based on this experience, in our ongoing and future programs of research we plan to keep community-based co-researchers engaged to help co-design future projects and potential interventions to address the issues they face which lead to an increased burden of diabetes-related adverse events.

\section{Author affiliations}

${ }^{1}$ Department of Medicine, University of Calgary Cumming School of Medicine, Calgary, Alberta, Canada

${ }^{2}$ Department of Community Health Sciences, University of Calgary Cumming School of Medicine, Calgary, Alberta, Canada

${ }^{3}$ Department of Cardiac Sciences, University of Calgary Cumming School of Medicine, Calgary, Alberta, Canada

${ }^{4}$ Patient Partners, Toronto, Ontario, Canada

${ }^{5}$ Department of Family Medicine, University of Calgary Cumming School of Medicine, Calgary, Alberta, Canada

${ }^{6}$ Department of Medicine, Unity Health Toronto, Toronto, Ontario, Canada ${ }^{7}$ Department of Medicine, University of Toronto, Toronto, Ontario, Canada

Acknowledgements We would like to acknowledge the critical contributions of our additional group members who are not coauthors of this manuscript: Dwayne E Hunte, Jasmine, Cat, Ozzy, and Georgina Bird. We thank them each for their willingness to participate and engage in the research process described. We thank the Interdisciplinary Chronic Disease Collaboration team: Corri Robb for transcription services, Sarah Gil for graphic design, and Patricia Wiebe for research administration. Linda Monteith-Gardner was instrumental in the photovoice project and Patricia 0'Campo helped with the concept mapping. Nishan Zewge-Abubaker and Tadios Tibebu facilitated the evaluation focus group. We are grateful for the staff of the TD Centre for Learning for hosting this community-based research group.

Contributors The study was conceived by DJTC and RBC with contributions from SWH, GLB and KM. The study topics were decided upon by AD, ML and MAD 
in conjunction with DJTC and RBC and the other members of the CDAC. Data collection was completed by DJTC, RBC, AD, ML and MAD. DJTC led the analysis of the data and wrote the first draft of the manuscript. All authors contributed significantly to data interpretation, critically revised and approved of the final submitted manuscript. DJTC is the guarantor for the manuscript.

Funding This work was supported by Alberta Innovates (20170233); the 0'Brien Institute for Public Health Vulnerable Populations Research Fund (2018VP03); and the Cal Wenzel Family Cardiometabolic Fund for Research at the University of Calgary (201801).

Competing interests None declared.

Patient consent for publication Obtained.

Ethics approval Conjoint Health Research Ethics Board of the University of Calgary (REB\# 18-1663), as well as the Research Ethics Board of St Michael's Hospital, Unity Health Toronto (REB\# 18-288)

Provenance and peer review Not commissioned; externally peer reviewed.

Data availability statement No data are available. Given the small sample size of this study, it is impossible for the data to be truly anonymized, therefore due to ethical considerations, data are not being made available.

Supplemental material This content has been supplied by the author(s). It has not been vetted by BMJ Publishing Group Limited (BMJ) and may not have been peer-reviewed. Any opinions or recommendations discussed are solely those of the author(s) and are not endorsed by BMJ. BMJ disclaims all liability and responsibility arising from any reliance placed on the content. Where the content includes any translated material, BMJ does not warrant the accuracy and reliability of the translations (including but not limited to local regulations, clinical guidelines, terminology, drug names and drug dosages), and is not responsible for any error and/or omissions arising from translation and adaptation or otherwise.

Open access This is an open access article distributed in accordance with the Creative Commons Attribution Non Commercial (CC BY-NC 4.0) license, which permits others to distribute, remix, adapt, build upon this work non-commercially, and license their derivative works on different terms, provided the original work is properly cited, appropriate credit is given, any changes made indicated, and the use is non-commercial. See: http://creativecommons.org/licenses/by-nc/4.0/.

ORCID iD

David J T Campbell http://orcid.org/0000-0002-5570-3630

\section{REFERENCES}

1 Macaulay AC, Commanda LE, Freeman WL, et al. Participatory research maximises community and lay involvement. North American primary care research Group. BMJ 1999;319:774-8.

2 Canadian Institutes of Health Research. Strategy for patient oriented research, 2019. Available: https://cihr-irsc.gc.ca/e/41204.html [Accessed 21 May 2020].

3 Patient Centred Outcomes Research Institute. About our research, 2020. Available: https://www.pcori.org/research-results/about-ourresearch [Accessed 21 May 2020].

4 Arnstein S. A ladder of citizen participation. Journal of the American Planning Association 1969;35:216-24.

5 Israel BA, Schulz AJ, Parker EA, et al. Community-Based participatory research: policy recommendations for promoting a partnership approach in health research. Educ Health 2001;14:182-97.

6 Turnbull AP, Friesen BJ, Ramirez C. Participatory action research as a model for conducting family research. $J$ Assoc Pers Severe Handicaps 1998;23:178-88.

7 Mosavel M, Simon C, van Stade D, et al. Community-based participatory research (CBPR) in South Africa: engaging multiple constituents to shape the research question. Soc Sci Med 2005;61:2577-87.

8 Wallerstein N, Duran B. The theoretical, historical and practice roots of CBPR. In: Minkler M, Wallerstein N, eds. Community-Based participatory research for health. Hoboken, NJ: Jossey-Bass, 2011.

9 Sloane DC, Diamant AL, Lewis LB, et al. Improving the nutritional resource environment for healthy living through community-based participatory research. J Gen Intern Med 2003;18:568-75.

10 Suarez-Balcazar Y, Early A, Maldonado A, et al. Community-based participatory research to promote healthy lifestyles among Latino immigrant families with youth with disabilities. Scand J Occup Ther 2018;25:396-406.
11 Coughlin SS, Smith SA. Community-Based participatory research to promote healthy diet and nutrition and prevent and control obesity among African-Americans: a literature review. J Racial Ethn Health Disparities 2017:4:259-68.

12 Tremblay M-C, Martin DH, McComber AM, et al. Understanding community-based participatory research through a social movement framework: a case study of the Kahnawake schools diabetes prevention project. BMC Public Health 2018;18:487.

13 Njeru JW, Patten CA, Hanza MMK, et al. Stories for change: development of a diabetes digital storytelling intervention for refugees and immigrants to Minnesota using qualitative methods. BMC Public Health 2015;15:1311.

14 Hallgren EA, McElfish PA, Rubon-Chutaro J. Barriers and opportunities: a community-based participatory research study of health beliefs related to diabetes in a US Marshallese community. Diabetes Educ 2015;41:86-94.

15 Thompson SJ. Participatory epidemiology: methods of the living with diabetes project. Int Q Community Health Educ 1999;19:3-18.

16 Harris J, Haltbakk J, Dunning T, et al. How patient and community involvement in diabetes research influences health outcomes: a realist review. Health Expect 2019;22:907-20.

17 Schulz AJ, Krieger J, Galea S. Addressing social determinants of health: community-based participatory approaches to research and practice. Health Educ Behav 2002;29:287-95.

18 Hwang SW, Bugeja AL. Barriers to appropriate diabetes management among homeless people in Toronto. CMAJ 2000;163:161-5.

19 Schlienger JL. Quelques chiffres récents propos Du diabète en FranceDiabetes in France: some recent data. Médecine des Maladies Métaboliques 2009;3:98-9.

20 Campbell DJT, O'Neill BG, Gibson K, et al. Primary healthcare needs and barriers to care among Calgary's homeless populations. BMC Fam Pract 2015;16:139.

21 O'Connell JJ. Dying in the shadows: the challenge of providing health care for homeless people. CMAJ 2004;170:1251-2.

22 Evans NS, Dowler EA. Food, health and eating among single homeless and marginalized people in London. Journal of Human Nutrition and Dietetics 1999;12:179-99.

23 Campbell DJT, Campbell RB, Booth GL, et al. Innovations in providing diabetes care for individuals experiencing homelessness: an environmental scan. Can J Diabetes 2020;44:643-50.

24 Kiser T, Hulton L. Addressing health care needs in the homeless population: a new approach using participatory action research. SAGE Open 2018;8:215824401878975.

25 Franco A, Meldrum J, Ngaruiya C. Identifying homeless population needs in the emergency department using community-based participatory research. medRxiv2021.

26 Rateau P, Moliner P, Guimelli C. Social representation theory 2012;2:477-97.

27 Zadeh S. The implications of dialogicality for 'giving voice' in social representations research. J Theory Soc Behav 2017;47:263-78.

28 Bogdan R, Biklen SK. Qualitative research for education: an introduction to theory and method. Allyn \& Bacon, 1998.

29 Arora A. Toronto - A data Story on Ethnocultural Diversity and Inclusion in Canada. Ottawa, ON: Statistics Canada, 2018.

30 Toronto Storeys. Toronto Ranks 12th On World's Most Expensive Housing Market List, 2019. Available: https://torontostoreys.com/ toronto-most-expensive-housing-market-list/ [Accessed 29 Jun 2020].

31 Gulliver-Garcia T. Which city in Canada has the most homeless people per capita and why? : Canadian Observatory on Homelessness, 2014. Available: https://www.homelesshub.ca/ resource/which-city-canada-has-most-homeless-people-capitaand-why [Accessed 20 Jun 2020].

32 Canadian Observatory on Homelessness. Community profiles: Toronto, 2019. Available: https://www.homelesshub.ca/communityprofile/toronto [Accessed 19 Jun 2020].

33 Gaetz S, Barr C, Friesen A. Canadian definition of homelessness, 2012.

34 Loney H. Background: Toronto's Regent Park. Global News, 2012.

35 Shallwani S, Mohammed S. Community-Based participatory research a training manual for community-based researchers, 2007.

36 Kane M, Trochim WMK. Concept mapping for planning and evaluation. SAGE Publications, Inc, 2006.

37 Grewal EK, Campbell RB, Booth GL, et al. Using concept mapping to prioritize barriers to diabetes care and self-management for those who experience homelessness. Int J Equity Health 2021;20:158.

38 Wang C, Burris MA. Photovoice: concept, methodology, and use for participatory needs assessment. Health Educ Behav 1997;24:369-87. 
39 Campbell R, Larsen M, DiGiandomenico A, et al. Illustrating challenges of managing diabetes while homeless using photovoice methodology. Canadian Medical Association Journal 2021;193.

40 Bignante $\mathrm{E}$. The use of photo-elicitation in field research. EchoGéo2010;11.

41 Hsieh H-F, Shannon SE. Three approaches to qualitative content analysis. Qual Health Res 2005;15:1277-88.

42 Kendell C, Urquhart R, Petrella J, et al. Evaluation of an Advisory Committee as a model for patient engagement. Patient Exp $J$ 2014;1:62-70.

43 Wallerstein N, Duran B. Community-based participatory research contributions to intervention research: the intersection of science and practice to improve health equity. Am J Public Health 2010;100 Suppl 1:S40-6.

44 Carman KL, Workman TA. Engaging patients and consumers in research evidence: applying the conceptual model of patient and family engagement. Patient Educ Couns 2017;100:25-9.

45 Hahn DL, Hoffmann AE, Felzien M, et al. Tokenism in patient engagement. Fam Pract 2017;34:290-5.

46 International Collaboration for Participatory Health Research Position paper 3: impact in participatory health research. Berlin: International Collaboration for Participatory Health Research, 2020.

47 Rhoades $\mathrm{H}$, Wenzel S, Rice E, et al. No digital divide? technology use among homeless adults. J Soc Distress Homeless 2017;26:73-7.

48 Brett J, Staniszewska S, Mockford C, et al. A systematic review of the impact of patient and public involvement on service users, researchers and communities. Patient 2014;7:387-95.

$49 \mathrm{ClHR}$. Considerations when paying patient partners in research.

50 Largent EA, Grady C, Miller FG, et al. Money, coercion, and undue inducement: attitudes about payments to research participants. IRB 2012:34:1-8

51 Madi BC, Hussein J, Hounton S, et al. Setting priorities for safe motherhood programme evaluation: a participatory process in three developing countries. Health Policy 2007;83:94-104.
52 Salihu HM, Salinas-Miranda AA, Wang W, et al. Community priority index: utility, applicability and validation for priority setting in community-based participatory research. J Public Health Res 2015;4:443.

53 Shippee ND, Domecq Garces JP, Prutsky Lopez GJ, et al. Patient and service user engagement in research: a systematic review and synthesized framework. Health Expect 2015;18:1151-66.

54 Olstad DL, Beall RF, Spackman E. A Subsidized healthy food prescription program for adults with type 2 diabetes who are experiencing food insecurity: protocol for a randomized controlled trial, modelling and implementation studies. Research Square 2021 https://www.researchsquare.com/article/rs-180761/v1

55 Riger S. Photo exhibit highlights 'dehumanizing' problems from being diabetic and homeless. Canadian Broadcasting Corporation, 2019. Available: https://www.cbc.ca/news/canada/calgary/ homelessness-diabetes-exhibit-1.5355133 [Accessed 17 June 2020].

56 Campbell D, DiGiandomenico A. The power of Storytelling through Photovoice, 2020. Pep talks: the patient engagement podcast Alberta SPOR Support Unit - Patient Engagement Platform, 2020. Available: https://soundcloud.com/patientengagement/episode-9-the-powerof-storytelling-through-photovoice [Accessed 20 Jun 2021].

57 Campbell DJT, DiGiandomenico A. Actions on diabetes podcast. Diabetes Action Canada, 2021. Available: https://diabetesaction.ca/ actions-on-diabetes-podcast/ [Accessed 20 Jun 2021].

58 McCammon E. Food insecurity and diabetes. Diabetes Canada, 2019. Available: https://www.diabetes.ca/managing-my-diabetes/ stories/food-insecurity-and-diabetes [Accessed 20 Jan 2021].

59 Randall Anthony Communications. The challenge of healthy eating The Globe and Mail, 2019. Available: https://www.theglobeandmail. com/life/adv/article-the-challenge-of-healthy-eating/ [Accessed 20 Jan 2021]. 